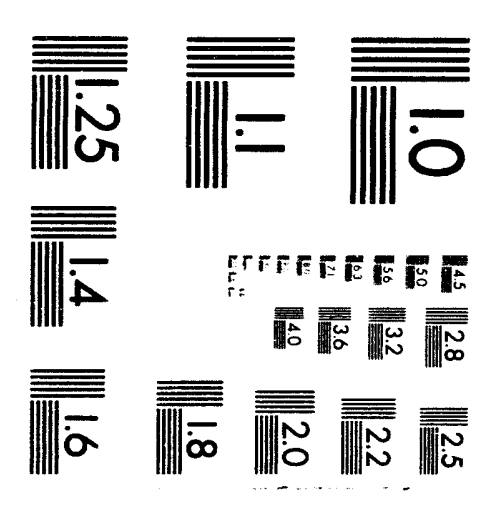



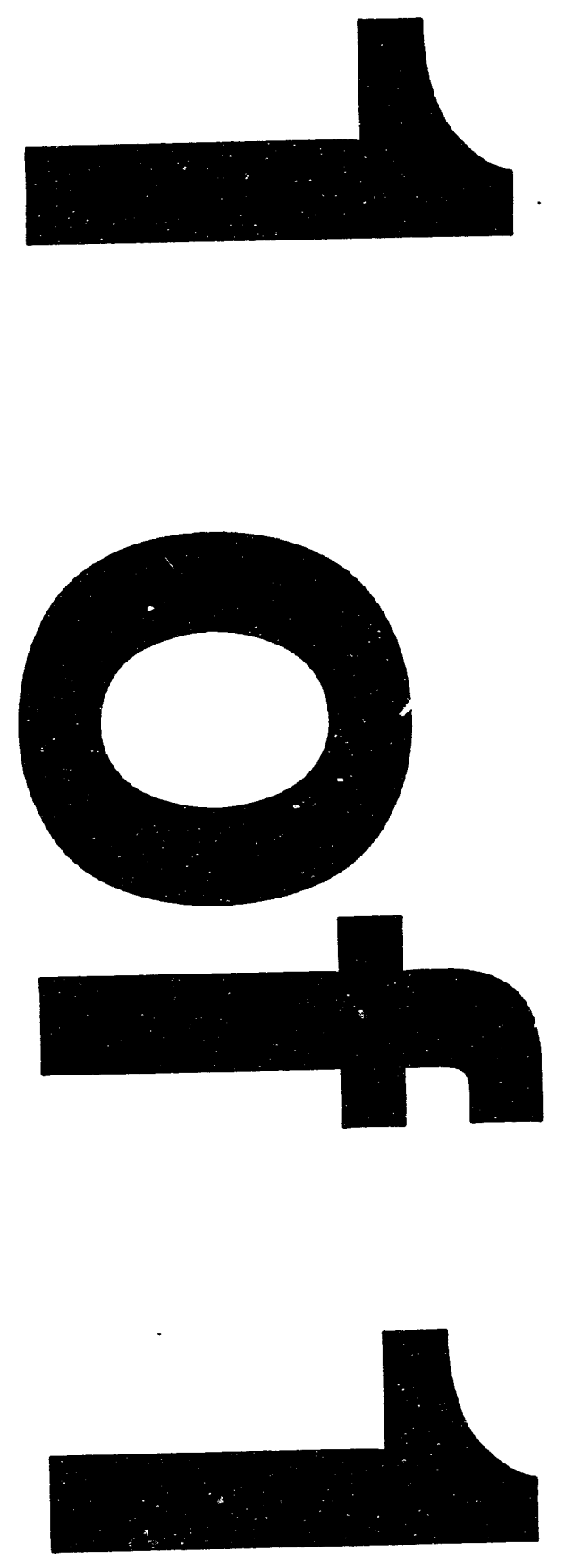
Quality Assurance Plan

for the Basic Environmental

Compliance and Monitoring Program

(BECAMP)

Edward H. Essington

\section{MASTER} DISTRIBUTION OF THIS DOCUMENT IS UNLIMITED 
Quality Assurance Plan for the Basic Environmental

Compliance and Monitoring Program (BECAMP)

Edward H. Essinglon

Effective Date: October 1, 1993

Author:

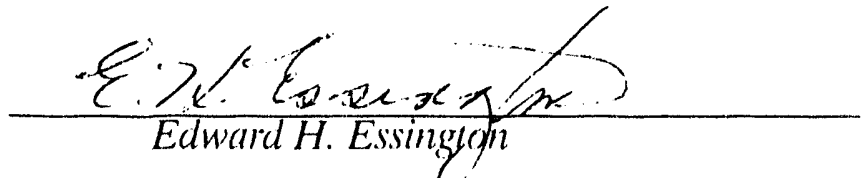

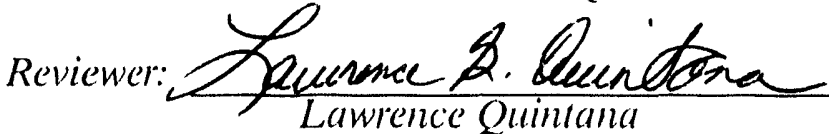

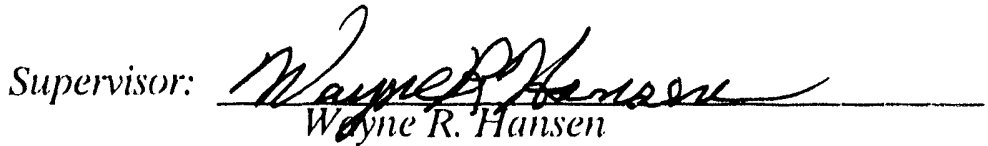




\section{CONTENTS}

$\begin{array}{ll}\text { ABSTRACT } & 1\end{array}$

$\begin{array}{lll}1.0 & \text { INTRODUCTION } & 1\end{array}$

2.0 BASIC QUALITY ASSURANCE REQUIREMENTS 4

3.0 DETAILED PROCEDURES 10

4.0 QUALIFICATION OF EXISTING DATA 14

5.0 PROTECTION OF COMPUTER SOFTWARE, DATA, AND DATA 14 SYSTEMS

6.0 QA REPORTS TO MANAGEMENT 16 
LA-11652-MS

Revision No. 1

Page 1 of 19

\title{
QUALITY ASSURANCE PLAN FOR THE BASIC ENVIRONMENTAL COMPLIANCE AND MONITORING PROGRAM (BECAMP)
}

by

Edward H. Essington

\begin{abstract}
This quality assurance plan (QAP) is designed to ensure that the methodologies and the data used for environmental cleanup and treatment studies at the Nevada Test Site are both usable and defensible. The QAP serves two purposes in this regard: (1) to guide the preparation of procedures for carrying out the tasks of the Basic Environmental Compliance and Monitoring program (BECAMP); and (2) to help management track the progress of those tasks.
\end{abstract}

\subsection{INTRODUCTION}

The Basic Environmental Compliance and Monitoring Program (BECAMP) was established in 1986 by the Department of Energy (DOE) to assess changes over time in the radiological and ecological condition of the Nevada Test Site (NTS) and to provide information needed for NTS compliance with applicable environmental laws. In addition, BECAMP is intended to assist the Department of Energy/Nevada Field Office (DOE/NV) in the areas of environmental restoration, technology development, environmental research, and environmental program reviews, as needed. BECAMP is an ongoing program that builds on the past work of the Nevada Applied Ecology Group and on other environmental studies relative to the NTS, such as 1) the radionuclide inventory on and around the NTS, 2) studies of radionuclide redistribution in the NTS environment, and 3) a dose-prediction model that uses data on the movement of radionuclides from soil to air, vegetation, animals, and, ultimately, man to estimate the impact of radionuclides on man and the environment.

BECAMP comprises ten Tasks (see Figure 1), one of which (Task 8, Quality Management) oversees the Quality Assurance Program for BECAMP. A major component of that program is the Quality Assurance Plan (QAP) presented in this document. As the first major revision to the original plan published in September 
1989, this QAP incorporates guidance from the DOE/NV Quality Assurance and Information Management divisions.

\subsection{Purpose}

This QAP is designed to

- guide BECAMP investigators in incorporating quality assurance (QA) into their various activities (experiments, studies, investigations), e.g., by satisfying applicable QA requirements set forth in ANSI/ASME NQA-1 (see Section 1.4, No. 3);

- supplement the QA efforts of BECAMP contributors, providing guidance as needed;

- provide instructions for the preparation of detailed procedures (DPs) for carrying out program Tasks or activities; and

- define the factors that must be considered to ensure that investigative and monitoring data are reliable.

\subsection{Scope}

This QAP applies to all activities of BECAMP investigators, contributors, and support contractors and may supplement the $Q A$ activities required by the investigators', contributors', or contractors' organizations.

\subsection{Description of BECAMP}

\subsubsection{Program Management Plan}

The Program Management Plan (PMP) (see Section 1.4, No. 9) describes the overall BECAMP objectives and outlines the requirements for meeting those objectives. The Annual Work Plan is an updated version of the PMP for the current fiscal year and constitutes the PMP for that year.

\subsubsection{Objectives}

BECAMP's objectives are to: (1) maintain and add to the body of knowledge of contaminants in surface soils at the NTS and study the movement of these contaminants within and around the site; (2) maintain and update human-doseassessment models for the NTS and its environs, and periodically field-test the 
predictions of those models; (3) maintain and update information on the spatial distribution and changes over time of the flora and fauna on the NTS; (4) address, in major peer-reviewed publications, important issues related to the potential impacts on the NTS of past, present, and future activities; and (5) evaluate NTS compliance with applicable environmental regulations.

\subsubsection{Participants}

BECAMP is composed of members of various organizations who :ontribute expertise in relevant disciplines in support of environmental evaluations $a_{1}$ the NTS. The current members are listed in Figure 2. They may conduct field experiments, collect and analyze samples and/or other data, or evaluate contaminant and environmental-health monitoring.

\subsubsection{Quality Assurance}

Each of BECAMP's objectives must be pursued in a way that satisfies the QA requirements of NQA-1 (see Section 2.0). In addition to assuring compliance with current regulations, fulfilling these requirements will ensure that data and conclusions regarding the long-term monitoring needs of the NTS are precise, accurate, complete, comparable, and representative, and that good scientific practice is exercised from the inception of an activity through to its final report. This level of quality is attained with the aid of DPs, some of which may refer to instructions in other documents and some of which may list the actual steps required to carry out the activity. The DPs will also identify the QA criteria that apply to that activity. The effectiveness of these QA measures will be verified periodically by means of surveys, audits, and peer reviews of final reports, publications, and operations, as deemed necessary.

\subsection{Applicable Documents}

Quality assurance is mandated by the regulatory requirements contained in the following documents.

1. DOE Order 5700.6C (8/21/91), "Quality Assurance."

2. DOE/NVO Order 5700.6B-10)(2/27/89), "Quality Assurance."

3. ANSI/ASME NQA-1 (1989 edition), "Quality Assurance Program Requirements for Nuclear Facilities."

4. ANSI/ASME NQA-1a (1986 edition), "Addenda to NQA-1." 
5. EPA-600-83-400 (February 1983), "Interim Guidelines and Specifications for Preparing Quality-Assurance Project Plans."

6. DOE Order 1360.2A (5/20/88), "Unclassified Computer Security Program."

7. DOE Order 1330.1C (1/12/90), "Computer Software Management."

8. DOE/NV Order $1330.1 \mathrm{C}-70$ (9/15/90), "Computer Software Management."

9. "Basic Environmental Compliance and Monitoring Program (Program Management Plan)."

10. UCAR-10220-88, "BECAMP Annual Work Plan, FY 1988."

11. UCAR-10220-89, "BECAMP Annual Work Plan, FY 1989."

12. UCAR-10220-90, "BECAMP Annual Work Plan, FY 1990."

13. UCAR-10226-91, "BECAMP Annual Work Plan, FY 1991."

14. UCAR-10220-92, "BECAMP Annual Work Plan, FY 1992."

\subsection{BASIC QUALITY ASSURANCE REQUIREMENTS}

In response to the 18 requirements set forth in NQA-1, we have developed the following $\mathrm{QA}$ requirements for BECAMP's activities.

\subsection{Organization}

\subsubsection{Management}

BECAMP is managed through the Environmental Protection Division of DOE/NV and is structured according to the chart in Figure 1. Quality assurance is required by the Program Manager and Scientific Director as part of the Quality Management Task assigned to a Quality Management Principal Investigator (QMPI). 


\subsubsection{Responsibilities}

The basic responsibilities for conduct of BECAMP are as follows:

1. The DOE/NV Program Manager (PM) and the BECAMP Scientific Director (SD) are responsible for conduct of the overall program and for the QA needs of BECAMP.

2. The PI has overall responsibility for overseeing and/or conducting Task activities as defined in the BECAMP PMP (or the current annual work plan) or as otherwise directed by BECAMP management.

The PI may delegate certain responsibilities to qualified personnel or support organizations.

The PI is responsibie for assuring that personnel conducting quality-related activities are properly trained and have necessary qualifications. Evidence of such training and qualifications will be documented in the Task or activity Resident File.

The PI is responsible for preparing (a) study plans that describe studies or experiments generating quality data and (b) DPs that provide detailed stepwise descriptions of the procedural activities, including those that support QA.

The PI is responsible for reporting progress and completing activities.

The PI is responsible for maintaining the Task or activity resident files, for assuring that documents are properly stored and archived, and for controlling information transfer from the Task or activity file to interested parties. A formal interface control is not needed for BECAMP operations.

3. Support organizations will provide services as identified by the $\mathrm{PI}$ and in keeping with the appropriate QA needs described in this QAP.

4. The QMPI will be responsible for executing various quality management activities identified in this QAP or as specified by BECAMP management. The QMPI will also update the QAP as necessary and will aid PIs in the preparation of DPs. Management may also direct the QMPI to review QA plans for contractor or PI organizations to assure appropriate QA coverage of the activities conducted for BECAMP. At a minimum, results of audits and surveillances conducted on BECAMP-related operations should be reported to the QMPI and to BECAMP management. 


\subsection{Quality Assurance Program}

The BECAMP QA program is described in this QAP. Study plans and DPs describe specific technical aspects of the activities to be performed and identify controls over quality-affecting activities (see Section 3.0). In addition, organizations contributing to BECAMP may require that their own QA program be followed. The BECAMP QA program is designed either to stand alone or to supplement those programs. In the event of conflict between the BECAMP QA program and a contributing organization's program, the PM will provide resolution.

\subsection{Design Control}

BECAMP will not conduct design control. Should a task require design of an item of significant cost, size, or impact on quality of data generated, the PI of that task will be required to document progress of the design, production, and acceptance phases.

\subsection{Procurement Document Control}

BECAMP will not control procurement documents; each PI will follow his/her organization's procurement rules or otherwise develop and control procurement documents for items that affect quality of data generated. Such documents may become part of the project documentation package, as described in Section 2.6.

\subsection{Instructions, Procedures, and Drawings}

Instructions, procedures, and drawings related to activities affecting quality are described in study plans and DPs (see Section 3.0) and other appropriate documents.

\subsection{Document Control}

Documents containing data or information affecting quality will be controlled by the PI. Each document should be uniquely identified; a page identifier system that contains at least a page counter should be used. A list or inventory of all identified documents generated for a Task or activity should be maintained by the PI.

Residen File: A resident file should be created for each major activity; it should contain copies or originals of all documents, including electronic storage files, pertaining to the activity. 
Detailed Procedures and Study Plans (see Section 3.0): The document will be clearly marked with document ID, revision number, and page number.

Dual Storage: Duplicates of critical records must be prepared, stored, and controlled to protect against loss. The PIs may provide that duality within their organization.

Archives: The resident file should be placed into the BECAMP archivestorage system (or other DOE/NV-approved archiving system) upon completion of the Task or activity. On a regular basis-defined by the PI or as specified by the PM or SD-photocopies of the resident file (new material only) should be provided to the archive system. Documents will be reviewed by the PI, or designate, for completeness and legibility before being placed in the archive system.

Document Review: This QAP shall be reviewed by the cognizant BECAMP line of command (PM and SD) with consultative input by PIs, Program Coordinator, or QMPI. A sign-off sheet may be used to track the approvals of DPs (see Figure 3). Reports describing the results of Tasks or activities should be peer-reviewed for technical content and reviewed by line management before release.

Modifications 10 QAP: Modification to this QAP may be made at any time but must follow the document-review process before being considered an official QAP for BECAMP. A revision must be clearly marked as such and dated.

\subsection{Control of Purchased Items or Services}

The procurement and control of items or services critical to generating quality data are the responsibility of the PI's organization. Control of measuring and test equipment is covered in Section 2.12. The PI will maintain a record of items and services purchased on behalf of BECAMP that documents receipt, inspection, acceptance or rejection, and identification of equipment (see Section 2.8).

BECAMP's interest in procurement of equipment will generally be to ensure that the equipment is received complete and in appropriate condition; that it performs according to manufacturer's specifications; and that services are performed in compliance with criteria set forth in guidance documents.

Documentation of tests to ensure proper performance of items or services is part of the Task's or activity's permanent record. Procurement of items or services for a Task or activity must also be documented as to specifications that might relate to quality of data generated upon use of the item or as a result of the service. 
Support organizations providing services for BECAMP must have in place a QAP or similar document that has been reviewed by the PI or QMPI and found consistent with BECAMP's needs. Results of the review will be maintained in the Task PI's resident file.

\subsection{Identification and Control of Items}

The PI's organization will be responsible for maintaining control of and identification of items used to generate quality data. In general, the PI will identify such items in DPs or other documents in the Task or activity resident file and indicate any additional controls needed. The PI must identify specific items in documentation relating to quality by a positive, unambiguous method such as serial number or property number.

\subsection{Control of Processes}

Processes used to generate quality data will be described in DPs (see Section 3.0) or other documents in the Task or activity resident file. The processes of concern will probably include methods for conducting field observations to quantify certain environmental parameters.

\subsection{Inspection}

Inspections of operations and records to verify conformance of an item or activity to manufacturer's specifications or requirements noted in DPs or other documents will be conducted by the PI or the PI's organization. The QMPI may conduct surveillances to provide an independent evaluation and to aid in recognizing conditions or potential conditions adverse to quality.

\subsection{Test Control}

BECAMP probably will not conduct tests of the type that require test control. Should any tests require control, they will be conducted according to the appropriate DPs and documented according to Section 2.6.

\subsection{Control of Measuring and Test Equipment}

Tools, gauges, instruments, and other measuring equipment (excluding such items as rulers) used for generating quality data will be controlled (see Sections 2.7 and 2.8) and calibrated or adjusted to maintain accuracy. The calibration procedure and reference standards used for calibration will be identified in DPs or otherwise 
identified in documents in the resident file. Control and calibration may by conducted according to requirements of the PI's organization.

\subsection{Handling, Storage, and Shipping}

Collection, packaging, preservation, and storage requirements for samples for evaluation will be described in a DP or study plan. Each sample will have a unique identifier permanently affixed to the sample container. Custody of the samples (who is responsible and where and how the samples are to be stored) will also be described in the DP. Transfer of custody requires a dated document signed by both the originator and the recipient of the samples. The document must list each sample by its unique identifier and must indicate conditions of the transfer. A copy of the completed ducument shall be placed in the resident file as a record of the chain of custody.

\subsection{Inspection, Test, and Operating Status}

Instruments or items must be inspected before use to assure proper calibration and operating status. The PI's organization or contractor will provide the labeling and control of items for inspection.

\subsection{Control of Nonconforming Items}

Instruments or items that cannot maintain calibration or proper functionality as required by the $\mathrm{Pl}$, or samples that become adulterated to the point that quality is affected, must be marked to indicate their status and must be segregated. They must not be used until repaired, calibrated, or independently qualified as conforming to requirements.

\subsection{Corrective Action}

Conditions adverse to quality will be identified promptly and corrected before attempts to generate quality data continue. When problems, inconsistencies, or deficiencies in data or procedures are detected by the PI, reviewers, or operators, or through surveys and audits, corrective action may be necessary. A Corrective Action Report (which may be in the form of a memo) describing the deficiency and its resolution will hecome part of the documentation derived for the Task or activity. Corrective action may consist of resampling, recalibration, reanalysis, or reevaluation by an independent expert. Corrective action requires identification, correction, and measures to prevent recurrence of technical problems that bear on the quality of the data or of the conclusions drawn from the data. Data that are at 
risk will be identified and marked or described. Organizations that have received incorrect data will be notifed by the PI and provided with new, correct data.

\subsection{Quality Assurance Records}

Accurate and complete records of any activity generating quality data will be required. These include, but are not limited to, any documentation relative to the initial considerations in activity design, DPs, any records developed during the execution of the DP, interim and peer-reviewed final reports of the activity, and any documents generated as a result of the QA activities. Several types of record may be generated: 1) laboratory or field notebooks, 2) laboratory or field collection or processing forms, 3) electronic storage media, (4) maps and photos, and 5) reports. Entries and corrections should be legible and reproducible.

\subsection{Audits}

The BECAMP QMPI will not conduct audits but may request audits to be conducted by disinterested parties. DOE/NV-QAD may also conduct audits as best meets DOE/NV management's needs. Audits will be conducted by a certified lead auditor in accordance with the amount of effort within a given Task or activity; audit results will be provided to BECAMP management. The QMPI will prepare an audit schedule at the beginning of each fiscal year. These audits are performed to verify compliance with all aspects of the QA program and to determine its effectiveness. Audits performed by a PI's organization may be accepted if the coverage is commensurate with the needs of BECAMP. Documentation of results of surveys and audits will be provided to the PM and maintained as project records by the QMPI.

\subsection{DETAILED PROCEDURES}

Detailed Procedures define technical requirements, constraints, and procedural steps of scientific activities that are to be conducted to meet BECAMPapproved PMPs, individual study plans, or activity descrintions. They are a vehicle for documenting instructions, checklists, operations, equipment, standards, and specific technology needs. DPs are generally more detailed and specific than study plans. For example, a DP may be specific for field sampling. In some cases, DPs may be more encompassing; for example, they may include details of the total study, starting with field sampling through a specific method of data evaluation and reporting. A DP may be written to include the elements and descriptions needed for a study plan and thus may satisfy the requirements of both. 
DPs will be required for any Task or activity involving, for example, sampling (including observational), sample analysis, and instrumental interrogation, and should be considered for other activities, for example, modeling and database operations. The DP must be reviewed for appropriate technical, QA, and statistical considerations and must be available for other reviews if assigned by the PM or the SD. The approvals will be officially noted on a sign-off sheet (see Figure 3 ) that will be part of the DP. A completed sign-off sheet will contain, at the minimum, the title, effective date, and approvals by at least one technical reviewer and the QMPI; other approvals may be required (e.g., statistics and peer review) by the PM or SD. Such additional reviews will be noted on the form. Results of each review will be in writing and will become part of the Task or activity documentation. The author and technical reviewer of the DP are automatically certified users; however, the PI may require additional training of those and other users.

Activities should not be conducted without an approved DP. However, certain activities not covered by an approved DP may be executed at the discretion of the PI or SD if the specifics of a DP (preferably a draft) are followed and appropriate documentation is created and maintained. This also pertains to emergency modifications to a DP.

DPs should contain, but not be limited to, the information described in the following sections.

\subsection{Purpose}

Explains what the DP is designed to do, including a concise description of the objective of the activity.

\subsection{Scope}

Defines the extent of application of the DP. The specific activities or Tasks included in or excluded from the DP can be stated.

\subsection{Definitions}

Defines special terms or names of items to avoid ambiguity.

\subsection{Responsibilities}

Identifies responsibilities of specific individuals, by organizational title, to indicate accountability for implementation of the various requirements of the procedure. 


\subsection{Training and Qualifications}

Outlines the requirements for training and qualifications, how training in use of DPs will be conducted, and what documentation will be maintained.

\subsection{Description of Activity}

If needed, provides a more informative description of the activity to augment the descriptions developed in the Purpose and Scope sections.

\subsection{Equipment, Supplies, or Special Items}

Lists special items (not hammers, measuring tapes, etc.) needed to conduct the activities described in the DP. Where appropriate, gives a brief description, particularly for any unusual item or any item that requires calibration.

\subsection{Stepwise Procedure}

Lists steps to be conducted (approved procedures may be referenced) in sufficient unambiguous detail that trained personnel can properly carry out the activities. Identifies operations that may be considered hazardous. Indicates appropriate actions to prevent injury or other hazardous conditions during execution of the DP. States the documentation that is to be completed for each step, where applicable.

\subsection{Applicable Documents}

Lists documents that apply to the DP (copies of difficult-to-obtain documents should be attached to the DP). For ease of document retrieval, copies of all referenced material should be included in the resident file.

\subsection{Support Services}

Identifies any support services that will be provided by persons or organizations other than direct BECAMP participants. States any special qualifications that will be required (e.g., licensed, approved).

\subsection{Records or Worksheets}

Notes any special record-keeping requirements (e.g., field-data sheets, direct electronic capture of data by data-acquisition systems). A method of accounting for 
all data sheets must be used and be under the control of the PI. For example, the PI may prepare a packet of data sheets that are numbered to account for each page and total number of pages (e.g., Page 3 of 10). After use, the packet is returned to the PI, who will see that all sheets are accounted for and will assess the impact of any missing or illegible information.

\subsection{Sample Storage and Finzdling}

Any requirements for handling, preparing, st sring, or shipping (transferring from one location to another) of samples will be identified (e.g., method of labeling and packaging samples upon collection) and clearly stated in the DP. Sample custody control is a requirement.

\subsection{Analytical Procedures}

Any specific sampling, preparation, or analytical procedure to be used that is not detailed in the DP must be referenced. When possible, copies of referenced procedures should be included in the resident file, either as separate documents or as an attachment to the DP.

\subsection{Calibrations}

Instrument calibrations should be made to standards supplied by National Institute of Standards and Technology (NIST), formerly National Bureau of Standards, or other applicable standards (e.g., as specified by the manufacturer). Methods of calibration and standardization not detailed in the DP shall be detailed in an appropriate reference.

\subsection{Data-Reduction Methods}

Methods used to reduce data and to test statistical inferences shall be clearly described; where appropriate, equations and definitions should be shown. Computer programs (codes, algorithms) used to reduce data must include version number and author and be a qualified version (see Section 5.2). Appropriate documentation shall be included as part of the resident file.

\subsection{Internal Quality Control}

Internal quality control (QC) needs will be identified in the DP. They may include the use of blind reference materials, blind replicates, standards, and check sources. Internal QC checks of sampling, sample preparation, and sample-analysis documentation will be conducted by the QMPI or PI. If anomalous results are found, 
they will be investigated to determine the cause and suggest a solution (see Section 2.16).

\subsection{Data or Sample Acceptance or Rejection}

Acceptance or rejection criteria for data or samples must be identified in the DP. In addition, independent peer review of reports of the data, including formal reports and reports to databases, should be conducted as a means of assuring the reliability of the data. Rejected data should be re-evaluated for applicability.

\subsection{QUALIFICATION OF EXISTING DATA}

Data not generated under an approved QAP (e.g., data generated before the initial version of this plan was in effect) may be evaluated and qualified for use. Four methods, or a combination, may be used:

1. peer review,

2. corroborating data,

3. confirmatory testing (e.g., rerunning portions of an experiment to generate additional data for comparison with the existing data), and/or

4. demonstration that the existing data were collected under a QA program comparable to that described in this QAP.

Documentation supporting the successful qualification or rejection of existing data, including corroborating data, results of confirmatory testing, peer review comments, or reference to sections of an acceptable QA program document, will be placed in the Task or activity resident file.

\subsection{PROTECTION OF COMPUTER SOFTWARE, DATA, AND DATA SYSTEMS}

BECAMP personnel are urged to use good data-, information-, and facilitymanagement practices to protect computers, software, and electronic data from loss or alteration. The PI's organization will provide guidance for the control and protection of computers and automated information.

\subsection{Data Sensitivity}

DOE Order 1360.2A (see Section 1.4, No. 6) requires a determination of the sensitivity of data and appropriate controls. Data generated by BECAMP and data 
from previous NTS environmental studies used by BECAMP were determined not to be Classified, Offical Use Only, or Privacy Act Information and that misuse, alteration, disclosure, or loss will not adversely affect national or other DOE interests. Sensitive data used by BECAMP contributors will be managed according to the user organization's rules.

\subsection{Software Control}

DOE Order $1330.1 \mathrm{C}$ and DOE/NV Order 1330.1C-70 (see Section 1.4, Nos. 7 and 8) cover computer software management and require the control of software proposed for use, under development, or being maintained and used. This includes software developed in-house, licensed from a commercial vendor, or obtained otherwise.

BECAMP PIs must document development of software used in collecting, processing, or storing quality data. The PI's organization will provide guidance and control for development, modification, procurement, and protection of software.

\subsubsection{Qualification of Computational or Analytical Software}

Software generated for BECAMP may be for programmable calculators, personal computers, or mainframe computers and includes simple computational codes or complex iterative model codes. The codes must be qualified to establish a referenceable version; modifications will be qualified as new versions. Documentation supporting qualification is to be maintained in the Task or activity resident file. Each series of computations will be appropriately identified with specific qualified software. Qualification consists of validation and verification.

5.2.1.1 Validation. Software is validated at the end of the software development process by ensuring compliance with software requirements and documentation of evidence that the model, as embodied in a computer code, is a correct representation of the process or system for which it is intended.

5.2.1.2 Verification. Software is verified by determining whether or not the products of a given phase of the software development cycle fulfill the requirements established during the previous phase and documentation of evidence that the computer code correctly performs the operations specified in a numerical model.

\subsubsection{Commercial Software}

Commercial software used for data reduction or manipulation shall be identified by name and version number. The documentation shall identify 
configuration management requirements and any appropriate qualification information.

\subsection{Data Base}

BECAMP maintains a data base for capturing, storing, and retrieving data and supporting information generated by the various contributors. PIs will submit data and supporting information to this data base. Instructions for preparing, protecting, transmitting, and accessing the data and supporting information either in printed form or on electronic media are supplied by the data base manager.

\subsection{Record Archives}

BECAMP utilizes the Coordination and Information Center (CIC) for archival storage of $\mathrm{QA}$ and other important documents relating to experiments and studies. Data generated from these studies that are to be made available to others are archived as described in Section 2.6. Instructions for preparing, protecting, transmitting, and accessing the records, primarily from the PI's Task or activity resident file, are supplied by the CIC. Documents submitted to the CIC are for longterm retention and their disposition and dissemination will be at the direction of BECAMP management.

\subsection{QA REPORTS TO MANAGEMENT}

No formal annual QA reports to the PM or SD will be required. Informal reports in the form of presentations at BECAMP planning and information meetings, annual summaries, memos and letters describing progress in QA areas, and speci I meetings with PM, SD, and PI representatives will provide the necessary information transfer and notification of QA status to management. Results of surveys and audits will be provided to the PM in writing. 


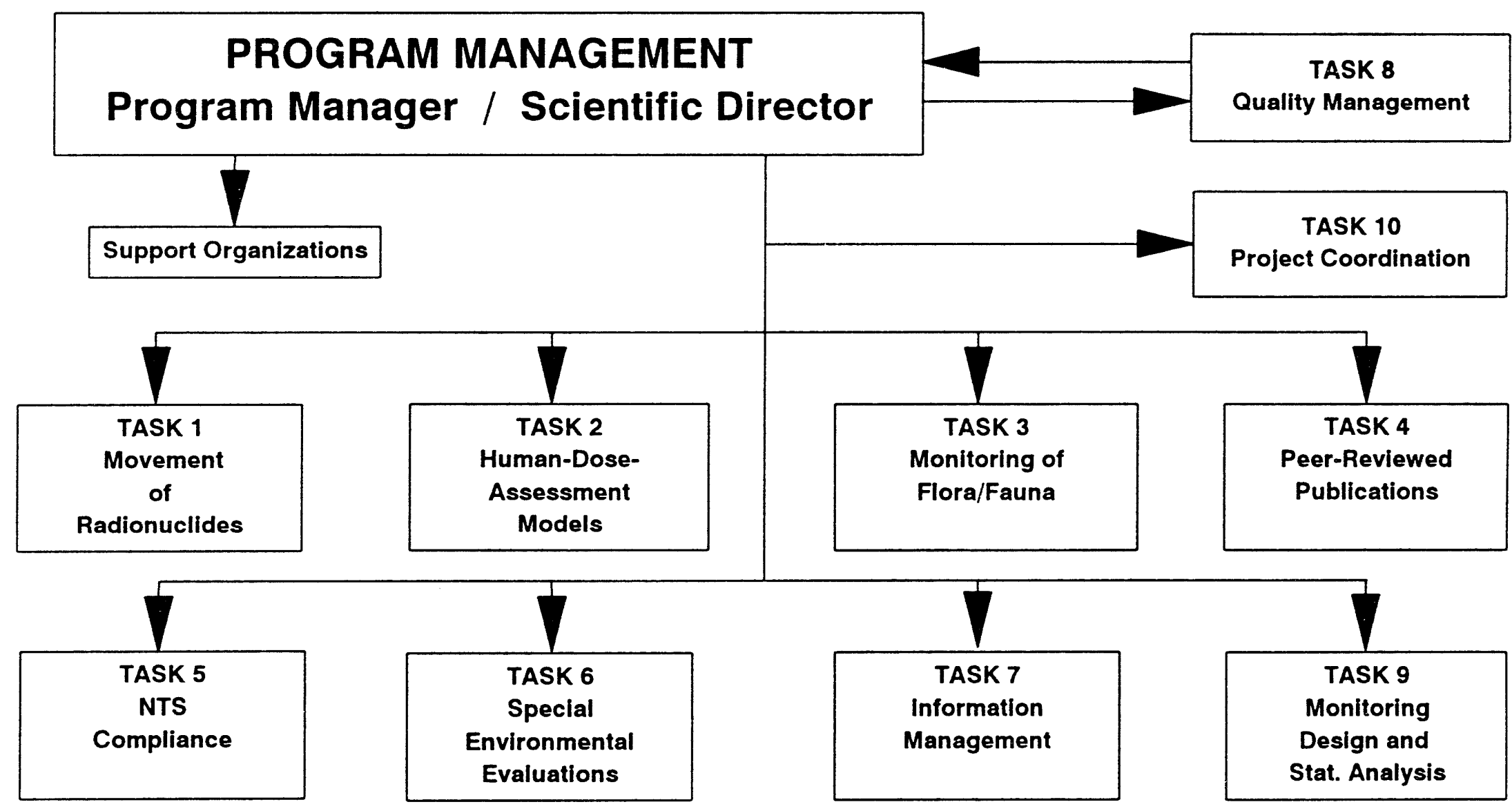

Figure 1. BECAMP Structure 
Figure. 2. List of Contributors to BECAMP.

\section{Program Manager \\ Movement of Radionuclides Task 1 \\ Human Dose-Assessment Models Task 2 \\ Monitoring of Flora/Fauna Task 3 \\ Peer-Rev. Publications \\ NTS Compliance \\ Compliance Monitoring \\ Archaeology \\ Endangered Species \\ Task 4 \\ Task 5}

Special Environmental

Evaluations

Information Management

Quality Management

Monitoring Design and

Statistical Analysis

Project Coordination

Scientific Director

Project Coordinator

NAEG Book

Task 6

Task 7

Task 8

Task 9

\section{DOE/NV}

J H. Shinn (LLNL)

J. R. Kercher (LLNL)

R. Hunter (REECo)

E. M. Romney (UCLA)

R. O. Gilbert (PNL)

S. E. Patton (LLNL)

L Pippin (DRI)

T. P. O'Farrell

(EG\&G/EM)

S. E. Patton (LLNL)

Task 10

C. Thompson (DRI)

E. Essington (LANL)

R. O. Gilbert (PNL)

R. McArthur (DRI)

L. R. Anspaugh (LLNL)

S. E. Patton (LLNL)

H. N. Friesen (RSN)

LLNL = Lawrence Livermore National Laboratory

LANL $=$ Los Alamos National Laboratory

REECo $=$ Reynolds Electrical and Engineering Co.

PNL $=$ Pacific Northwest Laboratories

DRI $=$ Desert Research Institute

EG\&G/EM = EG\&G/Energy Measurements

RSN = Raytheon Services Nuclear

UCLA $=$ University of California Los Angeles

NAEG $=$ Nevada Applied Ecology Group 
Figure 3. BECAMP Procedure Approval Form.

Effective Date

OBJECTIVE NO. TASK NO. DP IDENTIFIER

PRINCIPAL INVESTIGATOR

ORGANIZATION

[Enter procedure TITLE here]

SIGNATURES:

Preparer: [Type Name here]

Date

Technical Reviewer: [Type Name here]

Date

Quality Assurance: [Type Name here]

Date

Statistics: [Type Name here]

Date

COPIES TO:

D.R. Elle, BECAMP Program Manager

Chief, Environmental Science \& Technology Branch

Date Sent

US Department of Energy, NV

L.R. Anspaugh, Scientific Director

Lawrence Livermore National Laboratory

Date Sent 


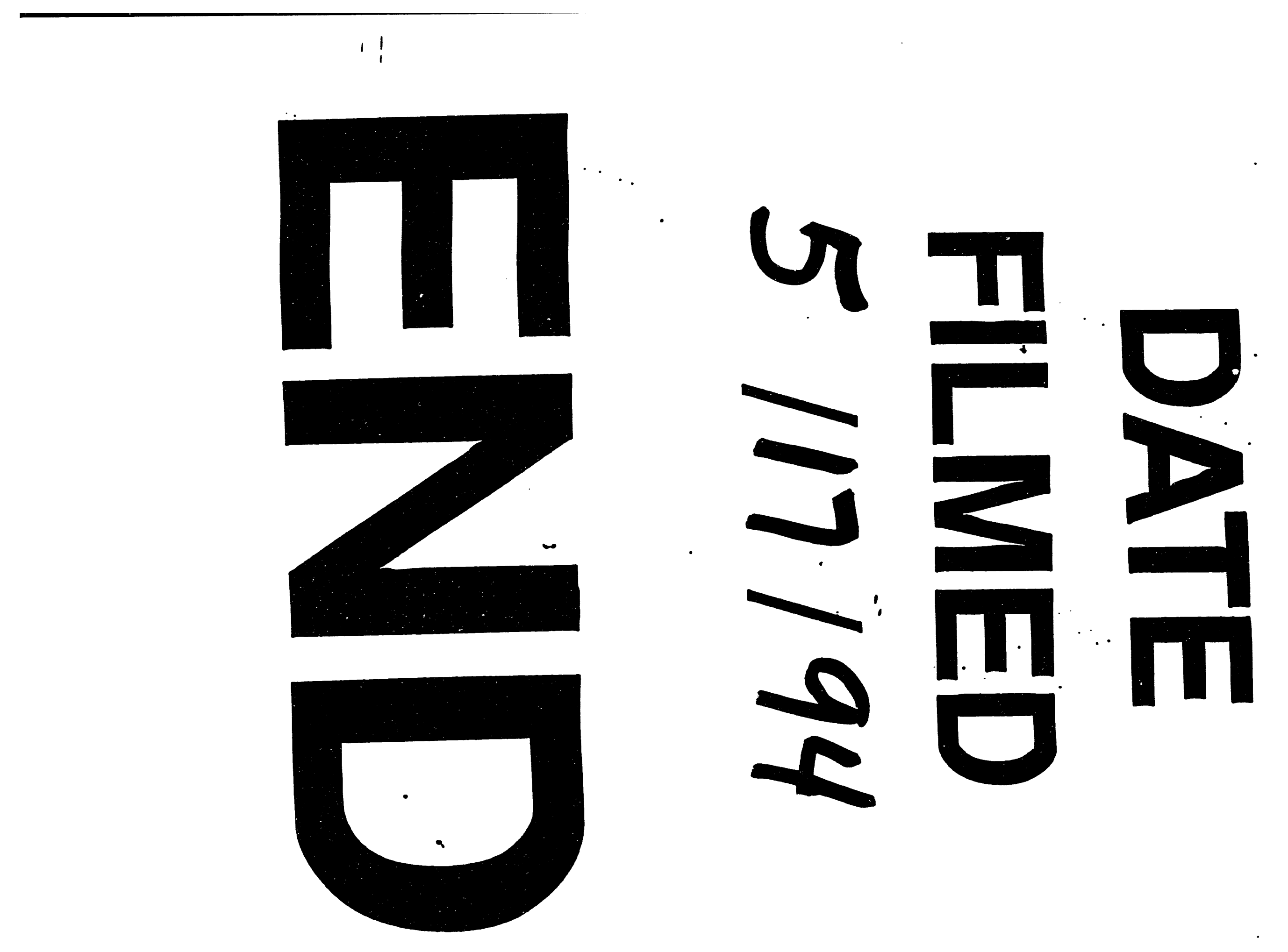


